\title{
Application of Schlieren Optical Visualization System in External Combustion and Internal Combustion Engine: A Review
}

\author{
Dahrum Samsudin ${ }^{1, a}$, M.D Anuar ${ }^{1}$, Safwan Othman ${ }^{1}$, Bukhari Manshoor ${ }^{1}$, \\ Amir Khalid ${ }^{1, b}$
}

${ }^{1}$ Combustion Research Group (CRG), Centre for Energy and Industrial Environment Studies

(CEIES), Universiti Tun Hussein Onn Malaysia, Parit Raja, Batu Pahat, 86400 Johor, Malaysia.

adahrumsamsudin@yahoo.com, bamirk@uthm.edu.my

Key Words: Schlieren optical, internal combustion, external combustion, Mixture Formation, Flame Development

\begin{abstract}
Schlieren optical visualization technique system is the unique technique due to the ability in producing a neutral image easily-interpretable image of refractive-index-gradient areas. The Schlieren system provides a method for viewing the flow through the transparent media and the most using this technique is to photograph the flow. This paper presents the review of the application of the Schlieren optical visualization system external and internal combustion engine in order to observe the fuel-air mixing and flame development during the burning process. The basic technique of Schlieren system, especially for Z-type and two mirror Schlieren system provide a powerful and clearly image to visualize the changes of the density in a transparent medium. This method can capture spray evaporation, spray interference and mixture formation clearly with real images. Analysis of optical image visualization observations reveals that the mixture formation of fuel and air exhibits the influence of the ignition and flame development. Thus, the observation of systematic control of the creation of a mixture of experimental apparatus allows us to achieve significant progress in the combustion process and will present the information to understanding the basic terms of reduced fuel consumption and exhaust emissions.
\end{abstract}

\section{Introduction}

The first Schlieren system was invented by Robert Hook in the 17th century and Schlieren technique developed in the 19th century by Toepler[1]. The Schlieren technique is an optical technique that detects density gradients occurring in a fluid flow in its simplest from light a slit is collimated by a lens and focused onto a knife-edge by a second lens, the flow pattern is placed between these two lenses and the diffraction pattern that results on a screen or photographic film placed behind the knife-edge is observed. The schlieren technique is often used to investigate heat and mass transfer process in gases and liquid[1-3]. Referable to the three dimensionality of the investigated processes, it's virtually inconceivable to get quantitative result about the density gradient from the schlieren image[1,2]. The primary reasons why Schlieren technique difficult to produce quantitative results because when the geometry is known or simple like sphere, cylinder or other it is possible to calculate the density gradient. Thither are many types of Schlieren technique, setup, but all the setup are based using the same principle [3-6].

\section{Experimental setup}

Figure 1 shown the basic setup to observe the experiment, the high-speed image obtained in this experiment used Schlieren technique[4-8] and the image will be continue process by using image processing to get the flame characteristics[7,9,10]. Schlieren Z-type with two mirrors reused in this experimentation. Xe-lamp is used as a light source and a $1 \mathrm{~mm}$ pin hole is used to form a point light source. 


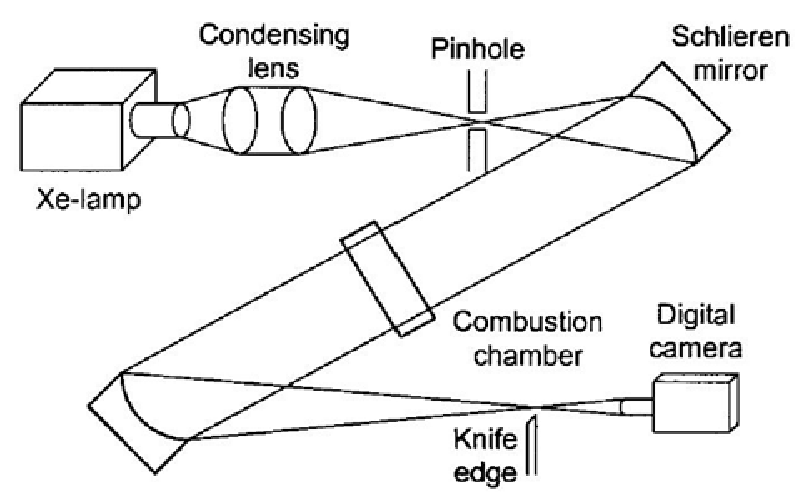

Figure 1: Schematics of Schlieren method[6]

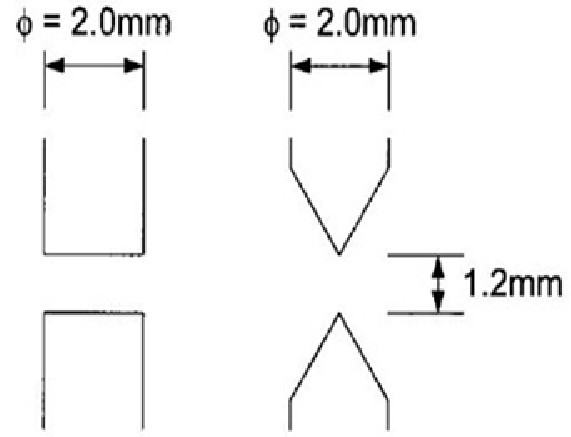

Flat electrode Sharp electrode

Figure 2: Shapes of electrodes[6]

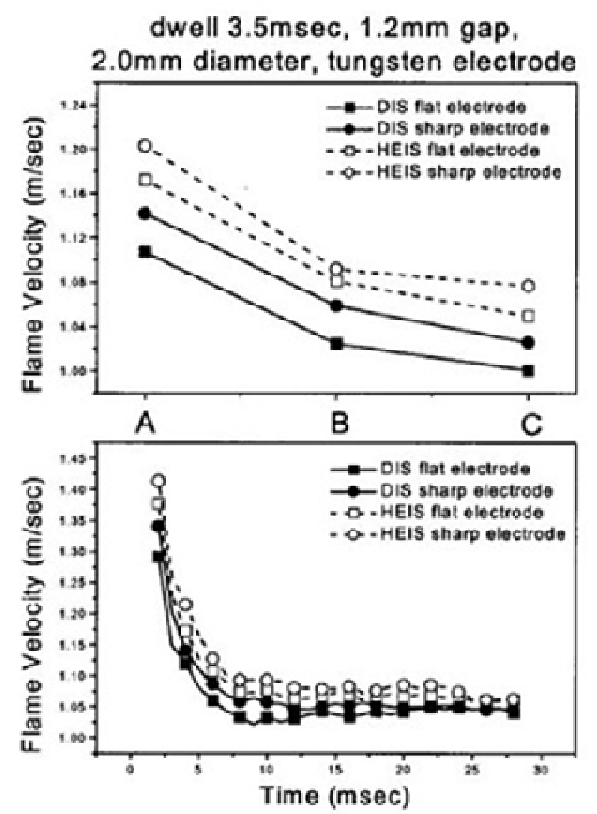

Figure 3: Effects of electrode shapes on flame velocity [6]

\section{Experimental Result}

The ignition process requires a proper distance between the cathode and anode electrodes, and if they are located too close, although discharge takes place, the mixture does not ignite[8,9]. The lowest bound of this length is experienced as the quenching distance, and it is a property of the mixture[11-13].The minimum ignition energy decreases with an increasing gap size until the gap size reaches the critical value, and, beyond this quenching distance, the minimum ignition energy remains nearly constant over a considerable range of the gap size $[5,7,8,14]$. The size of the spark kernel at which the rate of heat loss at its surface is precisely balanced by the rate of heat release throughout its volume[15-17].A larger spark gap requires greater voltage to go down the gap, an increase in gap width results in increased arc length more current is made along the spark to hold an almost constant voltage across it[6,7].

\section{Effects of electrode shape on flame propagation.}

The tested electrode shapes are presented in Figure 2.When the electrode shapes are altered, the discharge phase is shifted so that the energy transfer efficiency is too changed[11,14,19]. When the numbers of electrons emitted from differently shaped electrodes are the same, the smaller or more sharply tipped electrode produces a higher density of discharged current, which the glow phases to transmit to the arc phase. When the electrode tip becomes sharper, the ignition energy increases the increased energy causes faster kernel growth at location A, 


\section{The characteristic of flame propagation with mixture distribution}

Kihyung Lee studied a survey along the effect of stratified mixture formation on combustion characteristics in a constant volume combustion chamber[12]. Figure 4 shows the characteristics of flame propagation capture by high-speed camera. Where the authors find when mixture distribution is $100 \%$ of injection, the period of flame is short and its lager as the pre-mixture ration increases[11,18-21]. From the observation also the writers determine the pre-mixture is molded in the combustion chamber, combustion become unstable because the density of the stratified mixture around spark plug is cut[6,16,22-24].

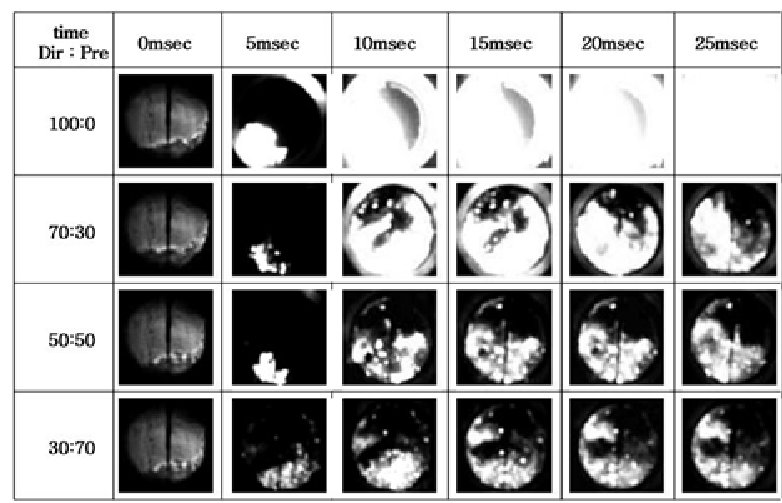

Figure 4: Flame propagation process $\phi=0.2 \&$ $\mathrm{Pa}=0.3 \mathrm{MPa}[12]$

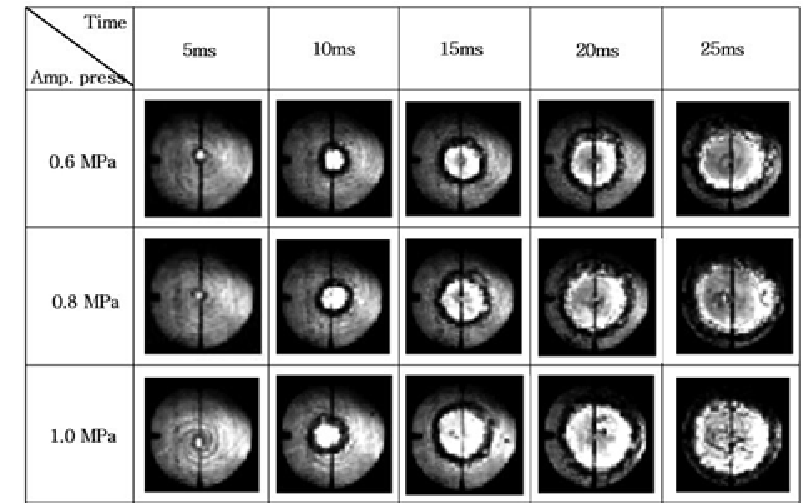

Figure 5: Fuel stratification flame propagation process with swirl intensity $(\phi=0.2 \&$ $\mathrm{Pa}=0.3 \mathrm{MPa})[12]$

Figure 5 shows the Fuel stratification flame propagation process with swirl intensity obtained d from Schlieren method. From the image it can be taken in that increasing the induced-air pressure will be increased the turbulence intensity and swirl ration[12,25-28]. As increasing the swirl intensity, will be shortest the period of fuel satisfaction round spark plug and it also had the vortex to become wider around fuel droplet[11,18,19].

\section{Conclusions}

The kernel formation and the flame propagation of a lean gasoline-air mixture are measured by the laser defection method, and they are visualized using a high speed digital camera. The experiment is performed in a constant volume combustion chamber, and several kinds of sparkplugs are designed and evaluated to investigate the effects of the ignition system, discharged energy and conjurations of the spark plug on flame kernel growth. The results obtained in this study are summarized as follows:

1. The spark plug design caused the arc where the minimum ignition energy decreases with an increasing gap size until the gap size reaches the critical value, and beyond this quenching distance, the minimum ignition energy remains nearly constant over a considerable range of the gap size.

2. When the electrode tip becomes sharper, the ignition energy increases the increased energy causes faster kernel growth.

3. The flame propagation speed is dependent on the mean equivalence ratio even in a heterogeneous mixture distribution.

\section{Acknowledgements}

The authors also would like to thank the Ministry of Higher Educations, Malaysia for supporting this research under Research Acculturation Grant Scheme (RAGS) Vot. R025 and Fundamental Research Grant Scheme (FRGS) Vot. 1054. 


\section{References}

[1] G. S. Settles, Schlieren and Shadowgraph Techniques. 2001, p. 376.

[2] H. Richard and M. Raffel, "Principle and applications of the background oriented schlieren (BOS) method," Meas. Sci. Technol., vol. 12, no. 9, pp. 1576-1585, Sep. 2001.

[3] A. Mazumdar, "Principles and Techniques of Schlieren Imaging Systems," 2013.

[4] C. Arcoumanis, D. R. Hull, and J. H. Whitelaw, "An Approach to Charge Stratification in LeanBurn, Spark- Ignition Engines," Oct. 1994.

[5] C. Arcoumanis and C.-S. Bae, "Visualization of Flow/Flame Interaction in a Constant-Volume Combustion Chamber," Mar. 1993.

[6] J. Song and M. Sunwoo, "Analysis of flame kernel development with Schlieren and laser deflection in a constant volume combustion chamber," Proc. Inst. Mech. Eng. Part D J. Automob. Eng., vol. 216, no. 7, pp. 581-590, Jan. 2002.

[7] J. Song and M. Sunwoo, "A Modeling and Experimental Study of Initial Flame Kernel Development and Propagation in SI Engines," Mar. 2000.

[8] J. Galle, C. Van De Maele, S. Defruyt, S. Verhelst, and R. Verschaeren, "Evaluation of Some Important Boundary Conditions for Spray Measurements in a Constant Volume Combustion Chamber," Apr. 2013.

[9] Amir Khalid and Bukhari Manshoor, "Analysis of Mixture formation and Flame Development of Diesel Combustion using a Rapid Compression Machine and Optical Visualization Technique", Applied Mechanics and Materials Vols. 315(2013), Trans Tech Publications, Switzerland, pp 293-298

[10] Amir Khalid, Norazwan Azman, Hanis Zakaria, B. Manshoor, Izzuddin Zaman, Azwan Sapit, Mutalib Leman, "Effects of storage duration on biodiesel properties derived from waste cooking oil", Applied Mechanics and Materials, Volume 554, 2014, Pages 494-499, DOI: 10.4028/www.scientific.net/AMM.554.494.

[11] M. S. Mansour, A. M. Elbaz, and M. F. Zayed, "Flame Kernel Generation and Propagation in Turbulent Partially Premixed Hydrocarbon Jet," Combust. Sci. Technol., vol. 186, no. 4-5, pp. 698-711, Apr. 2014.

[12] K. LEE, C. LEE, and H. JEOUNG, "A Study on the Effect of Stratified Mixture Formation on Combustion Characteristics in a Constant Volume Combustion Chamber," JSME Int. J. Ser. $B$, vol. 48, no. 2, pp. 265-272, Nov. 2005.

[13] J. Kim and R. W. Anderson, "Spark Anemometry of Bulk Gas Velocity at the Plug Gap of a Firing Engine," Oct. 1995.

[14] A. A. Abdel-Rehim, "Impact of spark plug number of ground electrodes on engine stability," Ain Shams Eng. J., vol. 4, no. 2, pp. 307-316, Jun. 2013.

[15] J. Zhou, K. Nishida, T. Yoshizaki, and H. Hiroyasu, "Flame Propagation Characteristics in a Heterogeneous Concentration Distribution of a Fuel-Air Mixture," Oct. 1998.

[16] O. Yaşar, "A new ignition model for spark-ignited engine simulations," Parallel Comput., vol. 27, no. 1-2, pp. 179-200, Jan. 2001.

[17] R. Herweg and R. R. Maly, "A Fundamental Model for Flame Kernel Formation in S. I. Engines," Oct. 1992.

[18] B. Ihracska, D. Wen, S. Imran, D. R. Emberson, L. M. Ruiz, R. J. Crookes, and T. Korakianitis, "Assessment of elliptic flame front propagation characteristics of hydrogen in an optically accessible spark ignition engine," Int. J. Hydrogen Energy, vol. 38, no. 35, pp. 1545215468, Nov. 2013.

[19] Amir Khalid and Bukhari Manshoor, "Effect of High Swirl Velocity on Mixture Formation and Combustion Process of Diesel Spray", Applied Mechanics and Materials Vols. 229-231 (2012), Trans Tech Publications, Switzerland, pp 695-699

[20] D. L. Lord, R. W. Anderson, D. D. Brehob, and Y. Kim, "The Effects of Charge Motion on Early Flame Kernel Development," Mar. 1993.

[21] T. Mantel, "Three Dimensional Study of Flame Kernel Formation Around a Spark Plug," Feb. 1992. 
[22] C. Pera, S. Chevillard, and J. Reveillon, "Effects of residual burnt gas heterogeneity on early flame propagation and on cyclic variability in spark-ignited engines," Combust. Flame, vol. 160, no. 6, pp. 1020-1032, Jun. 2013.

[23] K. Park, "The flame behaviour of liquefied petroleum gas spray impinging on a flat plate in a constant volume combustion chamber," Proc. Inst. Mech. Eng. Part D J. Automob. Eng., vol. 219, no. 5, pp. 655-663, Jan. 2005.

[24] S. H. R. Müller, B. Böhm, M. Gleißner, S. Arndt, and A. Dreizler, "Analysis of the temporal flame kernel development in an optically accessible IC engine using high-speed OH-PLIF," Appl. Phys. B, vol. 100, no. 3, pp. 447-452, Jul. 2010.

[25] D. K. Srivastava, K. Dharamshi, and A. K. Agarwal, "Flame kernel characterization of laser ignition of natural gas-air mixture in a constant volume combustion chamber," Opt. Lasers Eng., vol. 49, no. 9-10, pp. 1201-1209, Sep. 2011.

[26] T. Tahtouh, F. Halter, C. MounaÏm-Rousselle, and E. Samson, "Experimental Investigation of the Initial Stages of Flame Propagation in a Spark-Ignition Engine: Effects of Fuel, Hydrogen Addition and Nitrogen Dilution," May 2010.

[27] P. G. Aleiferis, Y. Hardalupas, A. M. K. P. Taylor, K. Ishii, and Y. Urata, "Cyclic variations of fuel-droplet distribution during the early intake stroke of a lean-burn stratified-charge sparkignition engine," Exp. Fluids, vol. 39, no. 5, pp. 789-798, Oct. 2005.

[28] [28] Amir Khalid, N.Tamaldin, M. Jaat, M. F. M. Ali, B. Manshoor, Izzuddin Zaman, "Impacts of biodiesel storage duration on fuel properties and emissions", Procedia Engineering, volume 68, 2013, Pages 225 - 230, Elsevier, 2013, DOI: 10.1016/j.proeng.2013.12.172.

[29] D. Eichenberger, "Effect of unsteady stretch on spark-ignited flame kernel survival," Combust. Flame, vol. 118, no. 3, pp. 469-478, Aug. 1999.

[30] K. E. Far, F. Parsinejad, M. Gautreau, and H. Metghalchi, "The Effect of Spark Electrode Geometry on Flame Kernel of Premixed Methane-Air Mixtures," in Volume 3: Combustion Science and Engineering, 2008, pp. 395-401. 